Owl nests on two sections of land. Bruce Kreba of Dunleath also found two nests not more than 150 vards apart. Sitanley Zazelenchuk of Siornoway located five nests within a two-mile radius, and the 22 yrung were all banded Time did not permit return visits to many of the nests that were located, but the total of 73 young banded from 18 nesits was still most satisfaclory.

I had never dreamed it would be possible to band over 300 owls in just over six months. It was only possible through the cooperation of many people and the energetic assistance provided by the boys whose names I have mentioned.

\title{
Mass Mortality of Western Grebes
}

by R. W. Nero, Saskatchewan Museum of Natural History

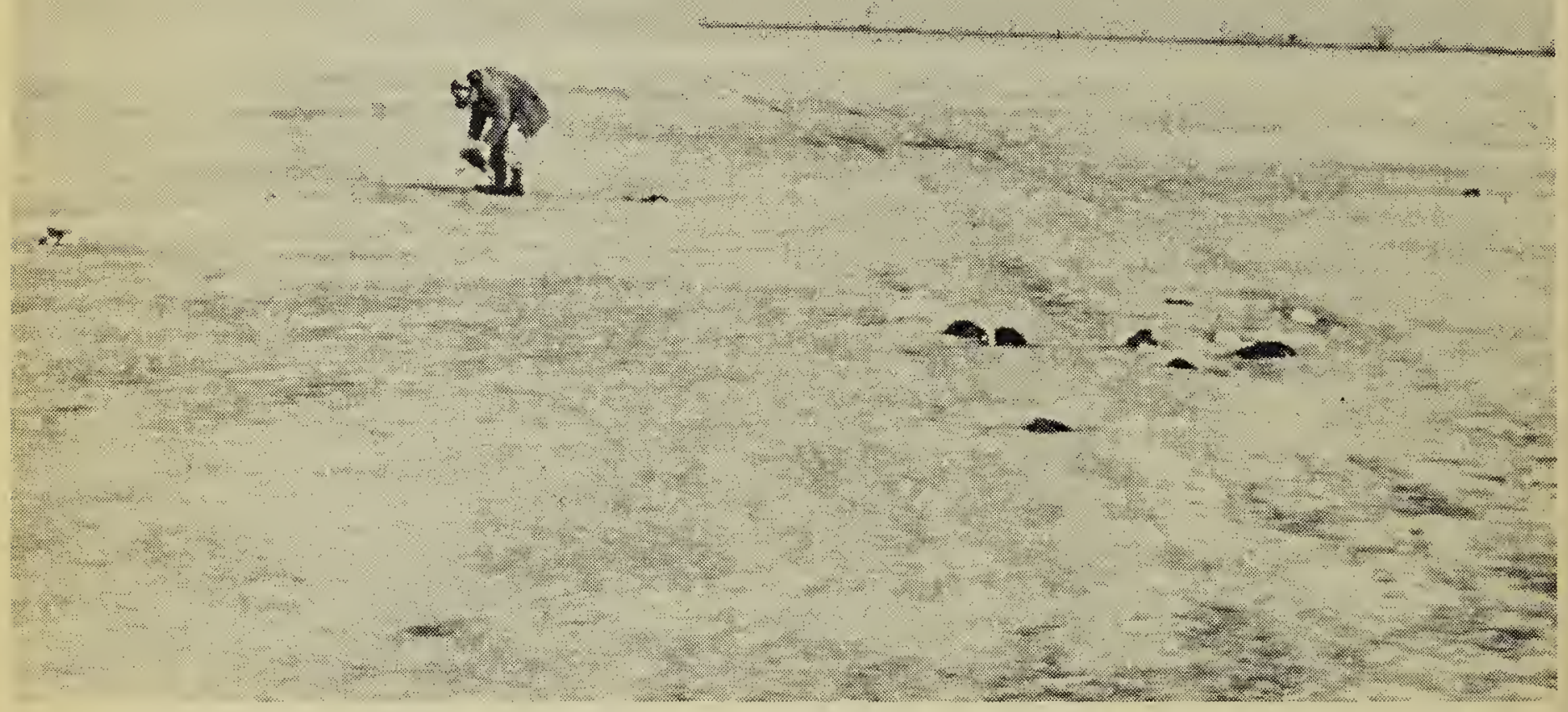

Photo by $F . W$. Lahrman

R. W. Nero examining Western Grebes frozen in the ice at Lake Newell, Brooks, Alberta.

On March 17, 1960, Fred Sharp (Provincial Naturalist, Ducks Unlimited), informed me of a mass mortality of the Western Grebe (Aechmophorus occidentalis) at a lake in southeastern Alberta. Probably more than 1000 grebes perished as the result of a sudden freeze-up during the period of November 13 to 16 , 1959, on Lake Newell, south of Brooks, Alberta. A report prepared by Sharp gives some details of his observations:

"On November 13th, on returning from a trip to southern Alberta J spent some three hours on the shores of Lake Newell observing the migration of waterfowl from the lake. The day was extremely cold: $-19^{\circ}$ with a 12 m.p.h. S.E. wind blowing. There was a snow cover of 3.5 inches, and the day was clear. However, with the weather conditions what they were the wind chill would be in the $-35^{\circ}$ zone. The bays on the lake were frozen over at this time as it had been quite cold since the start of the month. On November 5 th, for example, the temperature had dropped to $-7^{\circ}$ with a 13 m.p.h. wind. On the $13 \mathrm{th}$, vapor was rising from the open body of water in the lake, collecting into a cloud mass and falling as snow over the village of Tilley nine miles east of the lake. At this time approximately twothirds of the lake was still open, but what with the extreme cold and the wind, it was freezing in very fast; each incoming wave would wash up on the existing ice line and form a 
pyramid of rough ice, giving the ice on the lake the appearance of meringue on a pie.

"I observed Western Grebes come out of the vapor very low and spill into these ice caps; they were then unable to rise and due to the very rough condition of the ice were even unable to walk back to the open water. The ducks and geese would appear out of the vapor, but high up, and continue on their way south. On making an observation of the ice line at this time I was able to count some 20 to 30 stranded grebes on the ice. They all appeared to be alive. At 5:00 p.m. I lefit the lake with the flights of ducks becoming fewer, and just the odd flock of geese pulling out to the south. The odd Western Grebe was still bulleting out of the vapor and spilling into and on to the ice. I do not recall seeing one airborne grebe coming off the lake area.

"I did not return to the lake until December 20th. However, just prior to this date I had a report that a great many American Coots had frozen into the lake. When I examined the area I found only Western Grebes. Most of the dead birds were found frozen imbedded in the ice, along the freeze-line of November 13 to 16. Many were in groups of five and six, but carcases were found well dispersed all along the freezeline of this period. There was a bird or two every two or three hundred yards on the shoreward side of the freeze-line, indicating that these possibly were the birds that had become partly air-borne, then spilled in. There are two theories as to what happened: that they swam or were blown in along the ice line, then became locked in small open pockets of water and were unable to take off; or that they became partly frozen over with droplets of water whipped up by the wind, and became too heavy to get into the air. The latter theory seems reasonable since many birds were found with just their bills sticking out of the ice and many others were partly submerged.

"The following figures give weather data for the period leading up to and after the freeze-up: Nov. 5: low $-7^{\circ}$, wind S.E. at 13 m.p.h.; Nov. 12: low $-5^{\circ}$, wind S.W. at 15 m.p.h.;
Nov. 13: low $-19^{\circ}$ wind S.E. at 12 m.p.h.; Nov. 14: low $-3^{\circ}$, wind N.W. at 22 m.p.h.; Nov. 15: low $-15^{\circ}$, wind N.W. 25 m.p.h.; Nov. 16; low $-19^{\circ}$, wind S.E. at 13 m.p.h. (Data supplied courtesy Provincial Horticultural Station, Brooks.) After the last date given the weather warmed up to the mid twenties"

Fred Sharp, Charles Dougherty (Fish and Wildlife Officer, Alberta Dept. Lands and Forests), Fred W. Lahrman and I visited Lake Newell on March 26, 1960, at a time when the snow cover had melted away exposing the carcases of the grebes. I wanted to get a series for sex and age studies and in about two hours we gathered more than 100 dead grebes from two areas on the east side of the lake, along a streitch of less than one mile. These were found scattered along a line two to three hundred yards offshore, corresponding roughly to the edge of the icesheet at the time of the quick freeze-up. Owing to recent severe thaws most of the birds were lying on top of the ice surface or were in shallow pools of water in depressions evidently formed as the heat of the sun drawn by the dark bodies melted the surrounding ice. However, some grebes were still deep within the ice; in a few cases only the tip of a wing could be seen. Many were widely scattered, but there were some concentrations of eight to ten birds and in two places up to 25 were found within a hundred yard circle. Some were found lying side by side or huddled in groups; a few were still in an upright position, and several were found with their feet folded and tucked up on the back, concealed beneath the flank feathers and the wings. Sharp and Dougherty reported at this time that grebes were to be seen in a similar fashion along the full length of the east and south side of the lake, a distance of about 12 miles. We estimated on this basis that there were from 50 to 100 dead grebes in each mile, or a total of from 600 to 1200 . We felt this to be a conservative eistimate.

On the. next day (March 27) Lahrman and I visited M. Sven Bayer, a local naturalist who has lived for some 20 years on the southeast side of the lake. Mr. Bayer had also been 


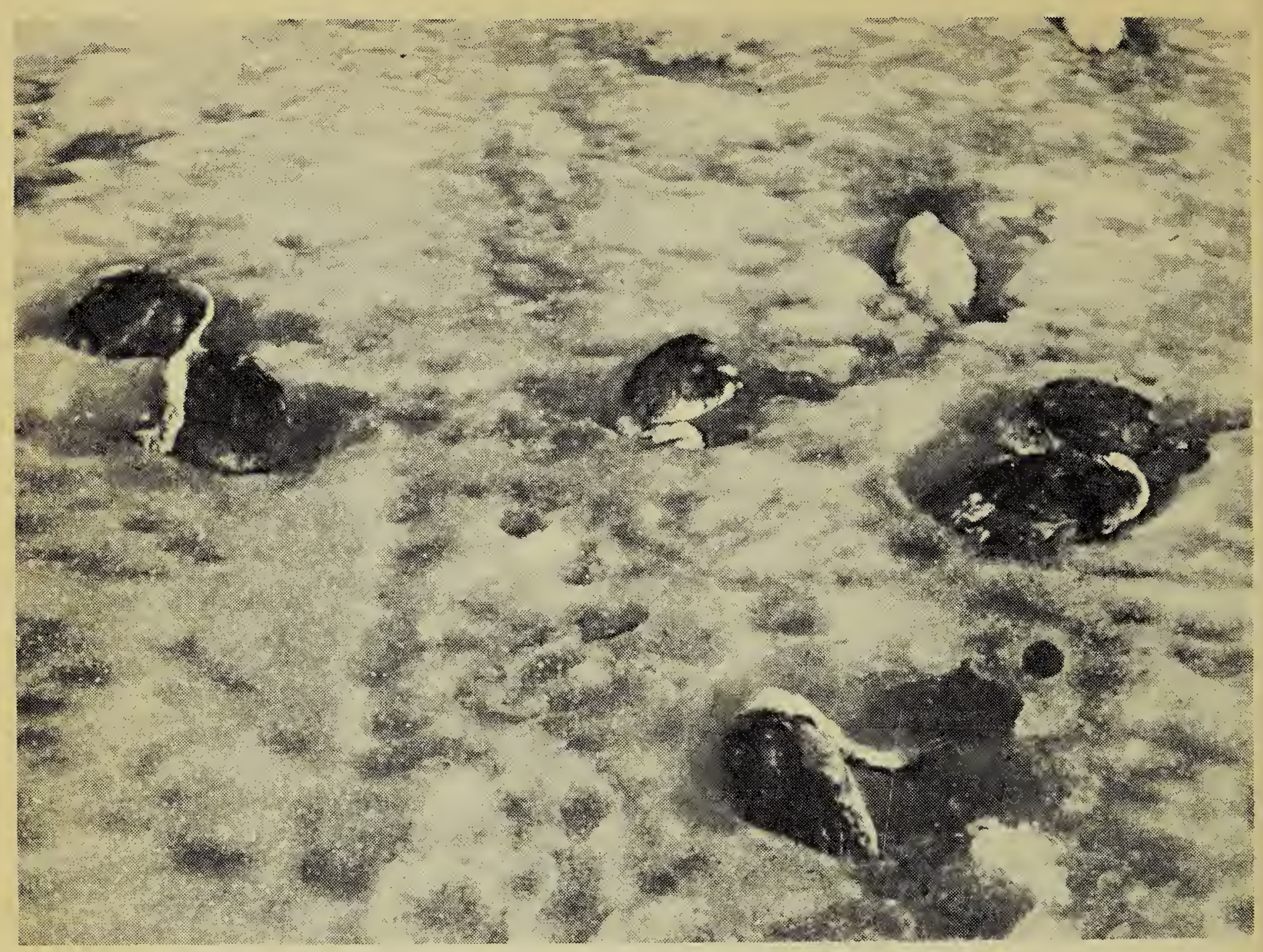

Photo by F. W. Lahrman

Western Grebes frozen in ice, Lake Newell

watching the grebes on the day of the freeze-up. His observations from the southeast lakeshore in front of his home agree with the account given by Sharp. Mr. Bayer stated that he thought the mortality was simply a matter of an unexpected and sudden freeze-up, and added that he had seen this happen to Western Grebes on several previous occasions, once during the last 10 to 15 years involving similar large numbers. Several Common Goldeneyes which had been on the lake, according to Mr. Bayer, simply flew off to safety during the storm. We have no record of mortality to any species other then Western Grebes in this incident. As A. C. Bent sitates: "This grebe, like others of its family, experiences considerable difficulty in rising from the water..." (1946. Life histories of North American diving birds. Dodd, Mead and Co., New York). Grebes, like coots, need to run along the surface of the water for a considerable distance in order to get up flight speed, and the combination of strong wind, waves, and verv low temperatures would séem sufficient to account for their inability to leave the lake.

Both Sharp and Bayer stated that Lake Newell is regularly used in spring and fall as a dispersal area or resting place for large numbers of grebes and that in the fall they usually remain until late in the year and close to freeze-up. Bent lists fall migration dates for Denver, Colorado, as October 25 to November 28. 